\title{
Qual edição e o que editar
}

\author{
What edition and what to edit
}

\author{
Alícia Duhá Lose* \\ Universidade Federal da Babia \\ Salvador, Bahia, Brasil \\ Célia Marques Telles** \\ Universidade Federal da Babia \\ Salvador, Bahia, Brasil
}

Resumo: De início, apresenta-se a definição de filólogo de L. S Picchio e, de imediato, remonta-se à discussão de F. de Saussure sobre filologia, chegando-se, então ao "regresso à filologia" de Paul de Man. Por fim, tomase a posição de Llored quanto à filologia. Ao preocupar-se com o objeto da Filologia, vai-se ao princípio do século XX com as nove etapas da filologia, apontadas por C. M. de Vasconcelos, que, na sua essência, são os mesmos com que se depara o filólogo nos dias atuais. Lembra-se, com B. Cerquiglini, a importância da escrita na sociedade medieval e chega-se, enfim, aos rascunhos dos escritores modernos e a importância dos dados de fala, alcançando-se o núcleo da investigação, que é o texto. Finalmente adverte-se que a filologia debruça-se sobre o documento, guardado, preservado nos arquivos. Explica-se a necessidade de o filólogo fazer edições de caráter conservador, preservando as características grafemáticas do texto, mas permitindo, também, a análise de outros níveis linguísticos no texto, como mostra R. Wright. Em seguida, passa-se a falar dos critérios de edição de textos, contrapondo antigas práticas com o comportamento dos editores na atualidade e a importância do texto fidedigno para o estudo do texto. E, então, passa-se a explicar a edição conservadora de textos na era da informática, ressaltando-se as tecnologias de que dispõe o editor de textos, lembrando a discussão trazida por M.C. P de Sousa, quanto à importância da cópia no meio digital e explicam-se as etapas da edição de um texto na era digital, chegando-se à edição digital hipertextual e, por conseguinte, à edição eletrônica. Nessa direção adverte-se o fato de que os princípios seguidos devem ser obedecidos a fim de que a edição digital possas cumprir o seu papel e tenha um espaço que a diferencia da edição estática feita nos moldes tradicionais. Conclui-se assinalando que o avanço tecnológico permitiu que a tarefa de proceder-se à transcrição do texto aumentou em velocidade e em variedades de formatos de apresentação, mas enfatizando-se ser a competência e a seriedade do pesquisador, por trás da decodificação dos caracteres e da escolha dos critérios, o ponto mais importante para a realização de um bom trabalho filológico.

Palavras-chave: Práticas de edições. Edição digital. Comportamento do editor. Edição conservadora.

Abstract: At first, the definition of philologist of L. S Picchio is presented and, immediately, it goes back to the discussion of F. de Saussure on philology, arriving, then, to the "return to the philology" of Paul de Man. Finally, Llored's position on philology is taken. Concerning the object of Philology, we go to the beginning of the twentieth century with the nine stages of philology, pointed out by C. M. de Vasconcelos, which, in their essence, are the same as that of the philologist today. The importance of writing in medieval society is recalled by B. Cerquiglini. Finally, we reach the drafts of modern writers and the importance of the data of speech, reaching the core of the investigation, which is the text. Finally it is warned that philology addresses the document, stored, preserved in the archives. It is explained the necessity of the philologist to make editions of conservative character, preserving the graphematic characteristics of the text, but also allowing the analysis of other linguistic levels in the text, as shown by R. Wright. Afterwards, we begin to talk about the criteria for editing texts, contrasting old practices with the behavior of editors in the present day and the importance of

* Doutora em Letras e Linguística (UFBA), professora da Universidade Federal da Bahia. Email: alicialose@gmail.com.

* Doutora de Filologia e Língua Portuguesa (USP), professora aposentada da Universidade Federal da Bahia e atualmente atua no Programa de Pós-Graduação em Língua e Cultura da UFBA. Email: cmtelles@ufba.br. 
reliable text for the study of the text. And then we begin to explain the conservative edition of texts in the computer age, highlighting the technologies available to the text editor, recalling the discussion brought by MC $\mathrm{P}$ de Sousa, regarding the importance of copying in the digital environment And explains the stages of editing a text in the digital age, reaching the digital edition hypertextual and, therefore, the electronic edition. In this direction it is warned that the principles followed must be obeyed in order that the digital edition can fulfill its role and have a space that differentiates it from the static edition made in the traditional molds. It is concluded that the technological advance allowed the task of transcribing the text increased in speed and in varieties of presentation formats, but emphasizing being the competence and the seriousness of the researcher, behind the decoding of the characters And the choice of criteria, the most important point for good philological work.

Keywords: Practices of issues. Digital edition. Editor behavior. Conservative edition.

\section{INTRODUÇÃO}

Começa-se com uma homenagem a Luciana Stegagno Picchio, retomando o seu conceito de filólogo. Em 1979, na conclusão de O método filológico (Comportamentos críticos e atitude filológica na interpretação de textos literários) (PICCHIO, 1979), a eminente filóloga italiana escreveu:

Por outro lado, acredito que seja sempre possível individuar no passado grandes espaços sincrónicos ideologicamente unitários que, com Michel Foucault, poderemos chamar epistemas. Filólogo é aquele que não considera intransponível o espaço entre um e outro epistema, coisa a que geralmente nos induz a mentalidade estruturalista, como o mostra a seu modo Zumthor, escolhido aqui pela riqueza das suas propostas como interlocutorantagonista deste diálogo à distância. Filólogo é quem, utilizando todos os instrumentos dos quais pode dispor, estudando todos os documentos se esforça por penetrar no epistema que decidiu estudar, procurar a voz dos textos e de um passado que já não considera sufocado pelos estratos sobrepostos (PICCHIO, 1979, p. 234).

No artigo Literatura e filologia (TELLES, 2005), assinala Picchio que entre os documentos antigos de Ferdinand de Saussure, editados por Rudolf Engler entre 1968 e 1974, existe um que trata da distinção entre literatura, filologia e linguística (SAUSSURE, 2004, p. 152-153). Em uma anotação que tem, como se sabe, data anterior a $1913^{1}$, escreve Saussure:

O estudo de uma literatura, do ponto de vista propriamente literário, é, para todo mundo, bastante distante dos estudos auxiliares que a ele se ligam, com um caráter mais técnico, e que são o campo de atividade especial do filólogo, como, entre outros, a crítica de textos, a crítica de manuscritos e de edições, a paleografia e a epigrafia, a explicação (hermenêutica) dos autores, a lexicografia, a gramática, a métrica de obras versificadas, etc. O filólogo poderá ainda, se for o caso, se tornar momentaneamente arqueólogo, jurista, geógrafo, historiador, mitólogo, etc., ocupando-se, geralmente, de tudo o que contribui, de perto ou de longe, para a melhor compreensão do espírito ou da letra dos autores. Não se tem dificuldade, também, para compreender qual é, ao lado da erudição puramente literária, o lugar que ocupa a

${ }^{1}$ Esses documentos foram datados por Rudolf Engler no artigo The Notes on general Linguistics, publicado nos Current Trends in Lignistics, (v. 13, n. 2, 1975. "European structuralism: Saussure"). 
erudição ou a ciência filológica, ainda mais que o ensino clássico (pelo menos no caso das línguas mortas) teve sempre em vista esses dois objetos ao mesmo tempo.

Acontece frequentemente, em troca, haver menos predisposição para compreender que a filologia, por sua vez, se mantém distinta da linguistica.

Literatura e filologia. - $\mathrm{O}$ estudo de uma literatura abrange apenas, no sentido que geralmente lhe é dado, objetos que oferecem um interesse literário propriamente dito; assim, ele é bastante distinto, para todo mundo, das ramificações de conhecimentos auxiliares, de caráter mais técnico, que constituem, por excelência, o domínio da filologia, como crítica de textos, crítica de manuscritos e de edições, paleografia, epigrafia, gramática, lexicografia, prosódia, métrica, "hermenêutica" ou interpretação dos autores, etc. Qualquer um percebe o lugar que cabe legitimamente aos estudos filológicos assim como o que os separa dos estudos puramente literários, ainda mais facilmente porque o ensino clássico (pelo menos com relação às línguas mortas) incluiu sempre essas duas ordens de estudos, ao mesmo tempo, e tornou familiar, para nós, seu conceito respectivo. Na realidade, é tão pouca a tentação de confundi-los que se faz necessário lembrar que são apenas um, em última análise, sendo que a filologia não passa de um vasto comentário que se apõe a uma literatura. É essa finalidade absolutamente literária em seu objeto final que constitui, ao mesmo tempo, a razão de ser e a unidade da ciência filológica que, de outra forma, abrangeria os mais disparatados estudos. Ela abraça tudo o que pode contribuir, de perto ou de longe, para a melhor compreensão do espírito ou da letra dos autores, o que faz com que, além dos assuntos precedentes, o filólogo tenha, ainda, que se tornar, conforme o caso, arqueólogo, jurista, geógrafo, historiador, mitólogo, etc. Sobre a obra dos escritores se concentra a dupla atividade do filólogo e do [ ]. Filologia e lingüística: se ninguém confunde o literário e o filólogo, que se tocam tão de perto, em contrapartida é muito [ ] [2 (SAUSSURE, 2004, p. 152-153).

Paul de Man, em A Resistência à teoria (MAN, 1989, p. 43-48), fala no "regresso à filologia" no ensino da literatura, referindo-se aos "teóricos franceses mais controversos", Michel Foucault e Jacques Derrida, e lembrando que Nietzsche filólogo (não o niilista existencial) é "um ponto de referência freqüente para todos estes escritores" (MAN, 1989, p. 46-47). Assinala, então, Paul de Man:

Porquê, então, os gritos de condenação e os apelos à mobilização contra um inimigo comum? Parece que o regresso à filologia, quer ocorra casualmente quer como conseqüência de mutações filosóficas altamente conscientes de si mesmas, perturba as pretensões aceites como verdadeiras com as quais a profissão da literatura tem funcionado. Como resultado, a atribuição de uma função segura, ou até exemplar, cognitiva e, por extensão, ética à literatura torna-se na verdade muito mais difícil (MAN, 1989, p. 47).

Patrick Llored em um artigo sobre a obra de Jean Bollack (LLORED, 2001), assinala que Bollack deu-se como tarefa

[...] apprendre à lire les auteurs dans le seul but de retrouver le sens premier de leurs productions intelectuelles, c'est-à-dire l'oeuvre en soi. Mais cette entreprise de retour à la lettre est inséparable d'une reflexion sur les traditions de lectures qui font écran entre les textes et leur sens. C'est pourquoi la philologie de Jean Bollack peut se définir comme étant

2 Neste ponto o escrito é interrompido. 
inséparablement critique et herméneutique: elle est critique au sens où elle se veut analyse des jugements portés sur les oeuvres tout au long de leur histoire jusqu'à aujourd'hui, et cherche à neutraliser les effets de l'histoire culturelle qui s'exercent contre l'oeuvre ellemême; elle est herméneutique en ce sens qu'elle veut comprendre le texte en lui-même et, plus précisement, son sens tel qu'il est construit, pensé et réfléchi dans l'oeuvre elle-même ${ }^{3}$ (LLORED, 2001, p. [1]).

Finalmente, afirma Llored, a filologia não é apenas uma arte da leitura baseada numa hermenêutica repensada e retrabalhada em profundidade, mas também, e é isso que talvez hoje pareça iconoclasto para alguns, um conhecimento crítico da utilização das obras e das condições nas quais leituras e não-leituras são praticadas: são, portanto, contra-leituras que nutrem em profundidade essa arte crítica. Desse modo, há aí uma considerável transformação do próprio estatuto da filologia, acompanhado de uma interrogação radical a propósito das razões da interdição dos sentidos. A sua ambição última é liberar os textos, antigos e modernos, do seu assujeitamento aos sistemas de pensamento da tradição e sobretudo da modernidade, sendo essa liberação futura a única condição da sua compreensão (LLORED, 2001, p. [31-32]).

Se forem retomadas as lições de Carolina Michaëlis de Vasconcelos (1946, p. 143), é possível ver que, na sua terceira aula do período 1911-1912, ela aponta os nove passos - implícitos nas notas de Saussure - do estudo filológico citados por Adolfo Coelho em A Lingua portuguesa, publicado em 1880 (VASCONCELOS, 1946, p. 144), neofilólogo que ela contrapõe ao filólogo clássico (VASCONCELOS, 1946, p. 142-143).

Uma primeira questão se apresenta: o que é objeto da Filologia? Desde a sua mais remota origem - com os sábios de Alexandria estudando os escólios de Homero - a Filologia mantém toda a sua atualidade e, como assinalava Carolina Michaëlis de Vasconcelos (1946, p. 143), ocupando-se de:

1. Estudo da língua

2. Estudo da métrica

3. Estudo das alusões históricas

4. Estudo dos autores, das particularidades biográficas, retiradas em especial da documentação sobre ele

5. Relações entre a sua obra e as demais representações literárias

6. A história dos manuscritos

7. A determinação da autenticidade dos testemunhos

8. A restituição do "texto do autor"

9. A determinação do valor literário e histórico do texto

\footnotetext{
${ }^{3}$ Traduzindo: “[...] aprender a ler os autores com o único objetivo de reencontrar o primeiro sentido das suas produções intelectuais, isto é, a obra em si. Mas essa tarefa de retorno à letra é inseparável de uma reflexão sobre as tradições de leituras que são o pano de fundo entre os textos e seus sentidos. Eis porque a filologia de Jean Bollack pode definir-se como sendo inseparavelmente crítica e hermenêutica: ela é crítica no sentido em que se volta para a análise dos julgamentos feitos sobre as obras ao longo da sua história até hoje, e busca neutralizar os efeitos da história cultural que atuam sobre a própria obra; ela é hermenêutica no sentido em que ela deseja compreender o texto em si mesmo e, mais precisamente, o sentido tal como ele foi construído, pensado e refletido na própria obra.".
} 
Essas nove etapas apontadas no trabalho de Carolina Michaëlis de Vasconcelos na sua essência os mesmos com que se depara o filólogo nos dias atuais - constituem, na realidade, três grupos de objetivos: o primeiro deles, o estudo da língua é o objetivo precípuo da Linguística; os de número dois a cinco, da Ciência da Literatura, resumidos no nono, a determinação do valor literário e histórico do texto; os de número seis a oito, da Crítica Textual (TELLES, 2000, p. 94-95). Mas essa preocupação não deve ser restrita ao filólogo.

Como se faz isso? Evidentemente que não tudo de uma só vez! Na realidade essas perspectivas distribuem-se em duas grandes áreas de estudo: as mudanças linguísticas e a crítica textual. O estudo da língua, a que se ligam o das alusões históricas, e o da métrica, constituem o objeto da primeira dessas áreas; os demais itens são objetivos da segunda, a crítica textual.

Nessa direção, Celso Cunha, em O ofício de filólogo (CUNHA, 2004), retomando G. Francescato, afirma que a linguística histórica e a filologia se confundiram em muitos dos seus objetivos, ressaltando não haver incompatibilidades entre o linguista e o filólogo “"...] ambos empenhados em procurar o agente das realidades palpitantes da vida através do estudo das grandes línguas de civilização, dos dialetos, dos mais humildes falares, da palavra conservada num texto atual ou remoto" (CUNHA, 2004, p. 354). A que acrescenta: "E nesse empenho visam a estudar o homem, que é o único agente da história" (CUNHA, 2004, p. 354).

É necessário não esquecer que o texto literário, escrito por excelência, é tão importante para a filologia textual quanto o discurso oral. A propósito da passagem ao escrito ou para o escrito na sociedade medieval entre os séculos VII e XI, lembra Bernard Cerquiglini em Éloge de la variante: histoire critique de la philologie (CERQUIGLINI, 1989), que é um movimento decisivo que leva essa sociedade de um estatuto oral e pré-letrado a uma mistura de oral e escrito, a partir de uma tipologia refinada de iletrismo, de quase-letrismo, de letrismo. O oral no período medieval convinha a uma sociedade regional e particular, mais voltada para os estatutos herdados do que para a dinâmica dos papéis sociais. $\mathrm{O}$ escrito, em troca, apropriação de um saber descontextualizado, pode ser um fator de progresso e de liberdade; não convém, portanto, desprezar uma oralidade medieval, livre, calorosa, e popular, vítima da repressão clerical e escriturária (CERQUIGLINI, 1989, p. 36-37). Os traços dessa oralidade, que se escondem no manto das variantes textuais, é que são importantes para Cerquiglini.

Nessa simbiose entre a oralidade e a escritura vale a pena lembrar o que diz Ana Teberosky na Introdução à coletânea de Claire Blanche-Benveniste, Estudios lingüísticos sobre la relación entre oralidad y escritura (TEBEROSKY, 1998), quando afirma que o oral não é homogêneo e que, ainda que haja uma distribuição de frequência desigual das formas elaboradas entre o oral e o escrito, raramente se ouve um oral elaborado. Por outro lado, muitas das formas do oral são espontâneas, enquanto poucos escritos o são. Nesse aspecto não elaborado do discurso, pode estabelecer-se um paralelo entre o oral bem elaborado e a escrita, ou entre o oral e todos os rascunhos do escrito (TEBEROSKY, 1998, p. 14). 
A esse propósito, lembra Ataliba de Castilho (1995, p. 70) que a construção é o processo central de constituição da linguagem, seja falada, seja escrita, por meio da qual é feita a organização mental, é veiculada a informação, exerce-se a ação sobre o outro e tem lugar a exteriorização dos sentimentos individuais. Essa constatação,continua ele, dá lugar a dois outros processos discursivos, o da reconstrução e o da descontinuação, os quais vai procurar integrar numa teoria unificada que não separe a língua falada da escrita (CASTILHO, 1995, p. 70). Como afirmam Almuth Grésillon e Jean-Louis Lebrave (1983) - falando dos manuscritos de autores modernos - os rascunhos (em francês brouillons) lembram o retorno de duas metáforas: de uma parte, os observadores falam da vertigem provocada pela desordem e pelo caos dos rascunhos; por outro lado, uma nebulosa, uma nuvem. Desordem, caos, nebulosa, ruídos que estão presentes, sobretudo nessa oralidade não elaborada, considerada em paralelo a esses rascunhos.

Claire Blanche-Benveniste (1998b, p. 50-51), ao considerar que os corpora de língua falada tomam como base a escritura ortográfica, chama a atenção para as dificuldades encontradas na escritura, pelo fato de essa não ser uma simples transposição da oralidade; é necessário, portanto, usar-se um código de transcrição, gráfico, mas não ortográfico. É ainda Claire Blanche-Benveniste (1998a, p. 138) que chama a atenção para a escritura de textos por pessoas inexperientes, para os quais se deve dar tanta atenção quanto para os textos estudados pelos filólogos. E, algumas vezes, esses dois tipos de texto estão muito próximos, quer se trate de uma escritura, ainda de adaptação, de um texto antigo, com base na escrita do latim, quer se trate de textos relativos à transcrição de depoimentos ou daqueles saídos de quem apenas sabe "ler e escrever".

E com isso retorna-se ao núcleo da investigação: o texto, sem o qual nenhuma das técnicas especializadas que se encontram na literatura moderna seria possível (FOWLER, 1994, p. 91).

Não seria supérfluo lembrar Umberto Eco ao afirmar que "a língua vai para onde quer, mas é sensível às sugestões da literatura", acrescentando que "sem Dante não haveria um italiano unificado" (ECO, 2003, p. 10). Adverte Eco, mais adiante, que:

É verdade que, para se transformar em língua falada por todos, o vulgar dantesco precisou de alguns séculos, mas se teve sucesso é porque a comunidade daqueles que acreditavam na literatura continuou a inspirar-se naquele modelo. E se não tivesse existido aquele modelo, não teria seguido o seu caminho a idéia de uma unidade política (ECO, 2003, p. 11).

A filologia, entretanto, não se debruça apenas sobre o literário, a sua preocupação é o documento, literário ou não literário, considerado produto cultural. Documento que se acha arquivado, guardado, preservado... O que nos leva a $O$ mal de arquivo de Jacques Derrida: "Nada é menos garantido, nada é menos claro hoje em dia que a palavra arquivo" (DERRIDA, 2001, p. 117).

Por outro lado, é preciso não esquecer que, em filologia textual, a relação grafemático-fonética leva a duas considerações relativas ao comportamento metodológico: a necessidade de se fazerem lições conservadoras nas edições dos textos 
manuscritos, a possibilidade de que tais lições permitem fazer-se uma descrição fonológica com base na scripta dos textos.

A questão inicial, entretanto, com que se depara o pesquisador de crítica/filologia textual não é um problema de método ou de técnica. Antes se acha relacionado ao tipo de texto com que se trabalha e à finalidade da edição pretendida. Não é ocioso, então, lembrar, com João Dionísio (2007), o fato de que a crítica textual não se reduz a uma técnica (DIONÍSIO, 2007, p. 125), aliado à observação do mesmo João Dionísio de que “a crítica textual não é disciplina de pensamento único” (DIONÍSIO, 2007, p. 115).

Desse modo, escolher qual a edição a ser feita não se resolve apenas com a definição dos diferentes tipos de edição oferecidos pelos estudiosos e repetidas nos dicionários terminológicos. É preciso adequar o tipo de edição à funcionalidade da edição buscada. Na apresentação do volume oito de Veredas, Luiz Fagundes Duarte (2007) afirma:

Historicamente, o filólogo tem algo de colecionador. Mais, tem o seu quê de conservador de museu, mesmo de taxidermista [...]

[...] Sábia e útil era, na verdade, tal idéia: dos pioneiros românticos até à filologia científica do século XX, as teorias e as técnicas da reprodução diplomática foram fornecendo edições cada vez mais rigorosas, dotadas de aparelhos filológicos cada vez mais descritivos, de tal modo que, pelo menos na opinião dos respectivos autores, em caso de destruição do original a sua memória subsistiria por meio da respectiva edição diplomática: a edição que descreve e reproduz mimeticamente, lugar a lugar e lição a lição, a universalidade que é um manuscrito - descreve as características dos suportes e dos instrumentos de escrita, da topografia dos fólios, dos hábitos caligráficos, das decorações; e reproduz o texto, transliterando-o, com a lição que ele tem no manuscrito, guardando-lhe a ortografia, as abreviações, a sintaxe, a variação interna, as lacunas, as repetições, enfim, tudo aquilo que faz dele um objecto único e irrepetível.

E esse tem sido, até hoje, o comportamento característico do filólogo, independentemente de se tratar de um manuscrito autógrafo ou do manuscrito de um copista medieval, de uma obra literária ou de um tratado de ciência, de um texto religioso ou de uma carta privada. [...] e o facto de, durante décadas, os filólogos suspirarem, em vão, por um método de trabalho e por um aparelho instrumental globais, que servissem a todos os filólogos e se aplicassem a todos os manuscritos, são disso exemplo (DUARTE, 2007, p. 12-13).

O mais importante dentro do comportamento metodológico do editor é ter como ponto de partida, sempre, uma lição conservadora, que vai permitir na sequência preparar o texto para o tipo de edição escolhida. Em A chamada lição conservadora na edição de textos (TELLES, 2009) e em A lição conservadora e a análise lingüistica do texto (GAMA; TELLES, 2001) já se chamou a atenção para esse fato, ressaltando-se as preocupações com a qualidade do texto editado e lembrando que para a descrição de sincronias passadas toda documentação de que se dispõe é escrita. Por outro lado, para a documentação da atualidade, a variedade de fontes de informação vai desde o texto escrito às imagens sonoras. No entanto, também para a transcrição do discurso oral, esse texto deve ser fiel à realidade linguística do emitente. Assim, quer se trate de edição crítica de texto medieval 
ou de texto moderno, o comportamento do editor crítico deve buscar preservar as características do corte sincrônico representado pela língua em que o texto foi vazado.

Não é diferente o tratamento que é dado nas edições semidiplomáticas. Desse modo, o texto vai possibilitar a verificação dos traços de fala transpostos para a escrita.

Como os níveis de análise de língua alcançados em edições conservadoras não se restringem ao fonético, nos textos escritos podem ser detectados fatos morfológicos, sintáticos ou mesmo discursivos, provenientes da variante de fala do responsável pela scripta (WRIGHT, 1998). No artigo Cambios linguísticos y cambios textuales, Roger Wright (1998) assinala que ao estudar a língua contemporânea podem ser aproveitados os meios modernos e os ouvidos, ficando estabelecido que não é possível limitar-se aos dados escritos. Entretanto, ao estudar-se a língua de época passada todos os dados disponíveis estão escritos. Desse modo é possível acompanhar as mudanças verificadas na apresentação dos dados textuais e às vezes tirar conclusões a propósito do fato de a língua falada também ter mudado. Essas conclusões, entretanto, não costumam ser simples, porque as relações entre escrita e fala são diferentes em épocas e comunidades diversas (WRIGHT, 1998, p. 303).

As ligações entre o escrito e o falado, continua ele ao tratar de mudança ortográfica e de mudança fonética, são mais complexas no âmbito da fonética, porque não é possível representar diretamente e de modo global todo o fonético (WRIGHT, 1998, p. 304). O problema reside, diz ele, na finalidade da escrita, que não é transcrever a fonética, mas indicar ao leitor a palavra e os morfemas que a compõem. Na realidade não importa que a forma escrita não represente exatamente a fonética da língua falada, se o leitor for capaz de reconhecer a palavra e os morfemas, pois ao ler-se um texto isto é feito para entender o conteúdo, e, para tanto, basta reconhecer as unidades léxicas (WRIGHT, 1998, p. 304).

Nessa direção, os erros ortográficos ajudam. Muitas vezes uma forma incorreta é tão corrente que se pode suspeitar ser correta (WRIGHT, 1998, p. 305). Conclui Roger Wright afirmando que a mudança linguística e a mudança textual são relacionadas, mas que se deve ter cuidado. Lembra, por fim, que a filologia tradicional e a linguística histórica precisam combinar-se entre si e com o senso comum. Assim, se poderá tirar proveito da experiência extraída do que se observa no mundo moderno e das relações estabelecidas entre a fala e a escrita (WRIGHT, 1998, p. 308).

É inegável o fato de que a escrita tem uma função preponderantemente comunicativa, ainda que de utilização mais restrita do que a fala, ressaltando-se o seu valor como documento da comunicação humana.

Por outro lado, no campo das transcrições de inquéritos linguísticos gravados recomenda-se o estabelecimento do texto através da chamada transcrição grafemática, buscando reproduzir fielmente a variante linguística registrada. Como lembra L. A. Marcuschi (2001), a passagem da fala para a escrita não é a passagem do caos para a ordem, mas a passagem de uma ordem para outra ordem. Assim, em qualquer hipótese, não devemos interferir na transcrição do texto. As transcrições de dados da oralidade devem, portanto, preservar as suas características de oralidade. 
Atente-se para os fatos de que a Filologia estuda o fato cultural e de que a língua é um dos elementos da cultura do homem. Nessa perspectiva, os estudos filológicos tanto se ocupam dos textos escritos, como da língua falada, pois, a língua é um ser histórico e a sua história confunde-se com a história do povo que a fala. Desse modo, o estudo da formação do português como das demais línguas românicas começa ao se tentar compreender a língua latina utilizada pelos romanos - na mais ampla expressão do termo - como uma língua viva, corrente, usada na comunicação diária por todas as camadas da população do Império Romano, a România, em todos os períodos da latinidade.

\section{OS CRITÉRIOS DE EDIÇÃO DE TEXTOS}

A maioria das normas de transcrição de textos medievais tende a uma "adaptação do texto à ortografia vigente em nossos dias", separando as palavras unidas, usando diacríticos, simplificando as grafias, desenvolvendo o til (sinal abreviativo) nas vogais nasais, pontuando o texto segundo o uso moderno! (CASTRO et al., 1973) Nada mais comprometedor para o texto. Não é muito diferente a situação para os textos quinhentistas. I. S. Révah, na sua edição do Ropica Pnefma (BARROS, 1983), declara que fornecerá ao leitor moderno um texto seguro, entretanto, "aligeirado de todas as complicações da ortografia quinhentista", justificando a sua escolha pelo fato de a edição trazer a cópia fac-similar do texto (BARROS, 1983, p. xxii).

Luis F. Lindley Cintra, ao editar os Foros de Castelo Rodrigo (CINTRA, 1984), procura respeitar as características do manuscrito, contanto que isso não constituísse obstáculo grave para o leitor moderno, buscando evitar que a leitura se tornasse desagradável ou apenas difícil (CINTRA, 1984, p. 14-15). Em sua Introdução à edição de A Demanda do Santo Graal de Joseph Piel, Ivo de Castro (1988) fala no repensar a posição modernizadora e uniformizadora que vigora entre os estudiosos - portugueses e brasileiros - desde os anos setenta (CASTRO, 1988, p. xxiv), ressaltando a atualidade da edição de Joseph Piel (ad quem 1934), cuja transcrição sem ser diplomática é uma leitura sobriamente conservadora como a das suas outras edições (CASTRO, 1988, p. xxiv). Diz Ivo de Castro:

Por não fazer concessões ao leitor não especializado, tal critério acha-se próximo das opiniões que hoje começam a prevalecer em matéria de transcrição de texto e que constituem um repensar da posição modernizadora e uniformizadora que se divulgou entre nós nos anos setenta, protagonizada pelas "Normas" do Boletim de Filologia, de que sou contrito cosignatário. Esta actualidade de critérios é um ponto a favor da publicação." (CASTRO, 1988, p. xxiv).

Esses critérios podem ser vistos no Prefácio à edição crítica do Livro da ensinança de bem cavalgar toda sela (PIEL, 1986. p. xiv-xvi) e Joseph M. Piel, no artigo Anotações críticas ao texto da Demanda do Santo Graal (PIEL, 1945), fala dos critérios adotados na sua edição da Demanda do Santo Graal. 
No entanto, existem textos que mantêm criteriosamente a grafia dos manuscritos, como é o caso da edição da Primeyra partida de Afonso X, preparada por José de Azevedo Ferreira (1980), afirmando o editor ter seguido escrupulosamente o texto, nele intervindo o menos possível (FERREIRA, 1980, p. cxxiv) ${ }^{4}$.

Por seu lado as chamadas edições semidiplomáticas (diplomáticas ou, ainda, diplomático-interpretativas) sempre procuraram manter as características da grafia do manuscrito. Um dos exemplos que pode ser citado é a edição diplomática do Livro dos conselhos de el-rei D. Duarte: Livro da Cartuxa, preparada por João José Alves Dias (1982), para a qual foi rigorosamente respeitada a grafia do texto original, com a manutenção da pontuação e das maiúsculas e minúsculas (DIAS, 1982, p. xvii).

Para o século XVI, toma-se o exemplo dos critérios de Emanuel Pereira Filho na sua edição do Tratado da Província do Brasil de Pero de Magalhães de Gândavo (1965). Pereira Filho justifica a sua escolha afirmando que tudo parecia indicar uma leitura com atualização ortográfica, fazendo a ressalva de que isso importaria, como sempre, em soluções críticas, disfarçadas em critérios pacíficos. Tal comportamento seria agravado pelo fato - afirma ele - de Pero de Magalhães de Gândavo apresentar claramente, nas Regras de ortografia, as suas convicções sobre a ortografia, muitas vezes em choque com uma "atualização". A partir do dilema estabelecido entre "violar" a atualização e "violar" os princípios de Gândavo, a opção de Pereira Filho recaiu em um "critério eclético", extremamente prudente: manteve o texto como se acha no manuscrito, permitindo-se fazer algumas alterações (GÂNDAVO, 1965, p. 49).

Ao tratar de manuscritos da Inquisição Portuguesa, Claude Henri Frèches (1986) observa que a escrita do século XVIII é muito mais fácil de ler do que a do século XVI (FRÈCHES, 1986, p. 302). Lembra a esse propósito que a scripta de um homem de idade, tendo vivido no século anterior, pode trazer marcas da escritura do seu tempo. Adverte, ainda, que os escrivães ou notários são diversos e que aos obstáculos provenientes da diversidade das idades acrescenta-se a diferença de nacionalidade (FRËCHES, 1986, p. 302). A seguir assinala:

L'édition critique idéale ne doit rien changer au texte authentique, que l'on designe habituellement par la sigle A (archétype) et qui peut, hélas! être détruit ou perdu. On risquerait gros à "reconstituer" un texte qui, par la suíte, serait rétrouvé. Il faut donc accepter de reproduire ce qu'on juge mauvais, soit par la verité, soit pour le goût. L'éditeur "critique" n'est pás chargé d'améliorer le texte, d'en rendre le sens plus aisé. Mais bien d'approcher celui-ci le plus possible de sa version originale. Ainsi l'ortographe será-t-elle scrupuleusement respectée, sauf em cas de lapsus (FRĖCHES, 1986, p. 302) ${ }^{5}$.

\footnotetext{
${ }^{4}$ Em especial, todo o capítulo 6 "Édition du texte (FERREIRA, 1980, p. cxxiv-cxLvi).

5 Traduzindo: "A edição crítica ideal nada deve mudar no texto autêntico, que se designa habitualmente pela sigla A (arquétipo) e que pode, ai! estar destruído ou perdido. Arriscar-nos-emos grosso modo a 'reconstituir' um texto que, em seguida, seria encontrado. É necessário, pois, aceitar reproduzir o que se julga ruim, seja pelo valor de verdade, seja pelo
} 
Assim, mesmo nas edições semidiplomáticas as transcrições podem não ser totalmente conservadoras.

Há ainda de se recordar, ao lado do texto fidedigno, a importância e o valor das chamadas edições modernizadas, reproduzindo um texto antigo segundo padrões ortográficos e linguísticos modernos (SPINA, 1994, p. 19), advertindo-se que para a crítica literária estas edições não têm valor algum. Essas edições buscam levar ao alcance do público de hoje a fruição de uma obra extraordinária, sem desvirtuar o primitivo sabor de sua linguagem (SPINA, 1988, p. xv), não se devendo prejudicar a legitimidade do texto, além de permitir a leitura fluente do mesmo. Ainda que seja um comportamento recomendável em alguns casos nas citações diretas, tal uso prejudica a utilização posterior do texto editado. Ora, pode afirmar-se que, se o objetivo a ser alcançado pelo editor é o estudo da língua, é melhor conservar os textos na sua grafia original.

\section{UM EXCERTO DA DEMANDA DO SANTO GRAAL $\left(\mathrm{f}^{\circ} .114 \mathrm{r}^{\circ}\right):$ A MORTE DE EREC}

Um exemplo de comportamento selecionado para apresentar é relativo a um capítulo de $A$ Demanda do Santo Graal, segundo as edições preparadas por Augusto Magne (1970, cap. LI, 340), Joseph Piel (1934/1988, cap. CCCXLIII), Irene Freire Nunes (1995, cap. 344) e Heitor Megale (1988, cap. 340), onde, em especial, se nota o tratamento totalmente modernizado que essa última edição dá ao texto.

A comparação entre a leitura paleográfica, conservadora (GAMA; TELLES, 2003, v.1, p. 463-5) e as três edições de $A$ Demanda do Santo Graal mostra o paralelo que se pode estabelecer:

a) por um lado entre a leitura paleográfica, como se pode ver na Fig. $1^{6}$, mais abaixo) e o conservadorismo da leitura de Joseph Piel (1934/1988);

Fo. 114r ${ }^{\circ}$, col. b, L.1-11

Quando erec se uio em terra nom se pode calar que nõ disese Certas dõ galuom ora $\mathrm{u}(\mathrm{os})$ vij aqui huu Ramo de couar diçe |e de maldade de meu caualo. que me matastes ora nõ podedes diz(er)

\section{Cap. CCCXLIII (PIEL 1934/1988, p.235)}

Quando Erec se vio en terra, nom se pode calar que nom dissesse: "Certas, Dom Galvam, ora vos vi aqui $\mathrm{u} \square \mathrm{u}$ ramo de covardice e de maldade, de meu cavalo que me matastes. Ora nom

gosto. O editor 'crítico' não é encarregado de melhorar o texto, de dar-lhe o sentido mais fácil. Antes deve aproximálo o melhor possível da versão original. Assim a ortografia será escrupulosamente respeitada, salvo em caso de lapsus".

${ }^{6}$ A Fig. 1 oferece a reprodução facsimilar ao lado da leitura paleográfica do excerto, na tentativa de mostrar o ponto de partida: o texto do manuscrito e uma possível leitura a ser feita no momento inicial do trabalho. 
poys me vir des morto que $\mathrm{u}(\mathrm{os}) \mathrm{me}$ matastes mais o falime $\square$ to de meu caualo mais nome $\square$ chal q(ue) q(ue)r q(ue) me

auenha de sta batalha $\mathrm{Ca}$ ataa aq(ui).

ouue 个ende a honrra le uossa desonrra Galuuã

que ajnda se coitaua muyto tanto q(ue) uiu erec em terra nõ atendeo mays $\mid e$ foilhe dar d(os) peit(os) do caualo le meteo em terra.

E erec cayo de Rosto |e smoreçeo da gram coyta que ouue le cailhe a espada. da maão |e o scudo. da outra parte. E galuã deçeo tanto q(ue) o asi viu Jaz(er) e foy aele $\mid \mathrm{e}$ ergue $\{\mathrm{u}\}$

lhe a. abaa da loriga |e meteolhe aespa da pello corpo le erec se stendeo como cõ coyta de morte. podedes dizer pois me virdes morto que vos me matastes, mais o falimento de meu cavalo. Mais nom me chal, que quer que me avenha desta batalha, ca ataa aqui ouve ende a honra e vos a desonra". Galvam que ainda se coitava muito, tanto que viu Erec em terra, nom atendeo mais e foi-lhe dar do peito do cavalo e mete[-o] em terra. E Erec caio de rosto e smoreceo da gram coita que ouve e cai-lhe a espada da mão e o scudo da outra parte. E Galvam deceo tanto que o assi viu jazer e foi a elle e erguei-lhe a abaa da loriga e meteo-lhe a espada pello corpo. E Erec se stendeo como com coita de morte.

b) por outro, esses dois comportamentos podem ser comparados em relação àqueles das outras três edições - a edição pioneira de Augusto Magne (1970, v. 2), eivada de problemas editoriais, a de Irene Freire Nunes (1995), onde se nota o tratamento modernizado dado ao texto, e a edição totalmente modernizada de Heitor Megale (1988).

\section{Cap. LI, 340 (MAGNE, 1970, v. 2, p.69)}

Quando Erec se viu em terra, nom se pôde calar, que nom dissesse:

- Certas, Dom Galvam, ora vos vi aqui uu ramo de covardice e de maldade, [no falimento] de meu cavalo, que me matastes. Ora nom podedes dizer, pois me virdes morto, que vós me matastes, mais o falimento de meu cavalo. Mais nom me em chal, que quer que me avenha desta batalha, ca ataa aqui | houve ende a honra e vós a desonra.

Galvam, que ainda se coitava muito, tanto que viu Erec em terra nom atendeu mais e foi-lhe dar dos peitos do cavalo e metê-o em terra e Erec caíu de rosto e smoreceu da grã coita que houve e cai[u]-lhe a espada da maão e o escudo da outra parte. E Galvam deceu tanto que o assi viu jazer e foi a êle e ergueu-lhe a abaa da loriga e meteu-lhe a espada pelo corpo, e Erec se estendeu como com coita de morte.

\section{Cap. 344 (NUNES, 1995, p. 259)}

Quando Erec se viu em terra, nom se pôde calar que nom dissesse:

- Certas, Dom Galvom, ora vos vi aqui $\mathrm{u} \square \mathrm{u} \square$ ramo de covardice e de maldade de meu cavalo que me matastes. Ora nom podedes dizer, pois me virdes morto, que vós me matastes, 
mais o falimento de meu cavalo. Mais nom me em chal que quer que me avenha desta batalha ca atá aqui $[114, \mathrm{~b}]$ houve ende a honra e vós a desonra.

Galvam, que ainda se coitava muito, tanto que viu Erec em terra nom atendeu mais e foi-lhe dar dos peitos do cavalo e metê-o em terra. E Erec caiu de rosto e esmoreceu da gram coita que houve e caí-lhe a espada da mão e o escudo da outra parte. E Galvam deceu tanto que o as si viu jazer e foi a ele e erguei-lhe a aba da loriga e meteu-lhe a espada pelo corpo e Erec se estendeu como com coita de morte.

\section{Cap. 340 (MEGALE, 1988, p. 268-9)}

Quando Erec se viu por terra, não se pôde calar, que não dissesse:

- Certamente, dom Galvão, ora vos vi aqui manifestação repentina de covardia e de maldade na falta de meu cavalo que matastes. Ora não podeis dizer, depois que me virdes morto, que me matastes, mas a falta de meu cavalo. Mas não me importo com o que quer que me advenha desta batalha, porque até aqui tive dela a honra e vós a densora [sic].

Galvão, que ainda se esforçava muito, assim que viu Erec em terra não esperou mais e foi-lhe dar dos peitos do cavalo e meteu-o em terra e Erec caiu de rosto e esmoreceu da grande dor que teve, e caiu-lhe a espada da mão e o escudo da outra parte. E Galvão desceu logo que o assim viu jazer e foi a ele e ergueu-lhe a aba da loriga e meteu-lhe a espada pelo corpo e Erec se estendeu com sofrimento de morte.

Desse modo, vai servir para mostrar a funcionalidade de duas leituras extremas (a conservadora e a modernizadora) e as divergências de comportamento dos editores críticos.

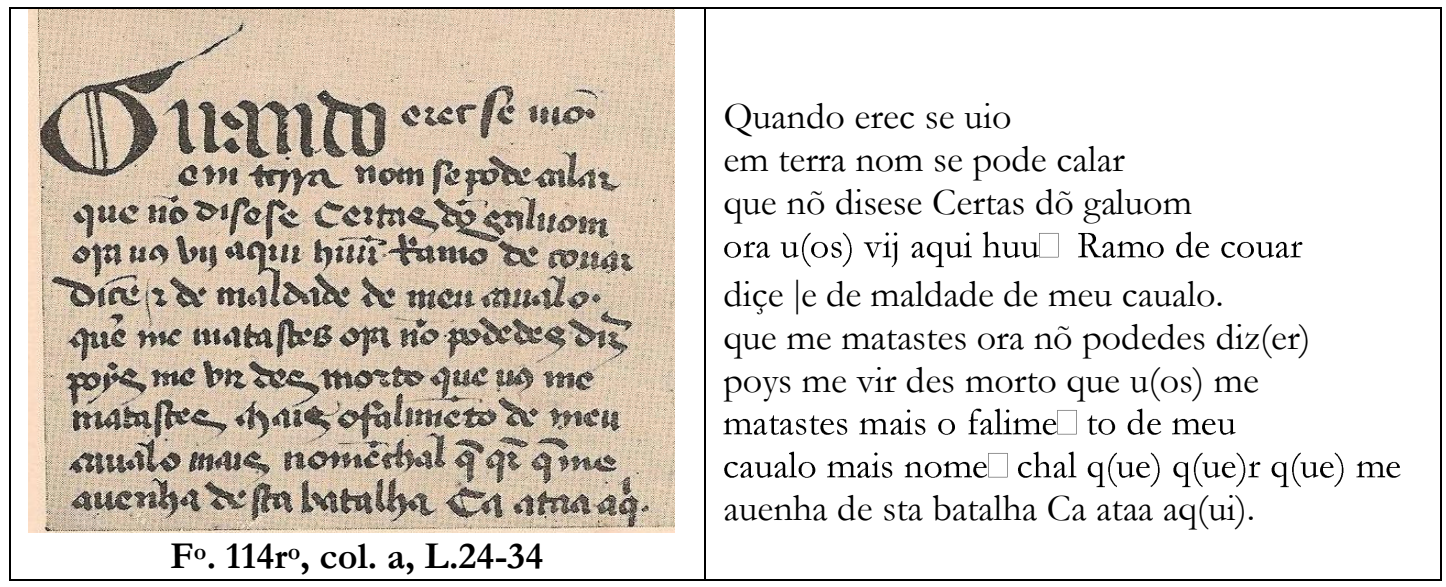




\begin{tabular}{|c|c|}
\hline 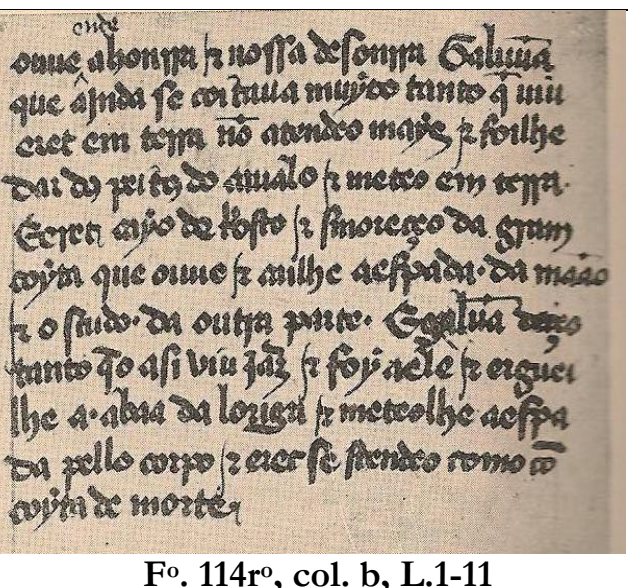 & $\begin{array}{l}\text { ouue } \uparrow \text { ende a honrra le uossa desonrra Galuuã } \\
\text { que ajnda se coitaua muyto tanto q(ue) uiu } \\
\text { erec em terra nõ atendeo mays |e foilhe } \\
\text { dar d(os) peit(os) do caualo |e meteo em terra. } \\
\text { E erec cayo de Rosto |e smoreçeo da gram } \\
\text { coyta que ouue |e cailhe a espada. da maão } \\
\text { |e o scudo. da outra parte. E galuã deçeo } \\
\text { tanto q(ue) o asi viu Jaz(er) e foy aele |e } \\
\text { ergue }\{\mathrm{u}\} \\
\text { lhe a. abaa da loriga |e meteolhe aespa } \\
\text { da pello corpo le erec se stendeo como cõ } \\
\text { coyta de morte. }\end{array}$ \\
\hline
\end{tabular}

Figura 1 - Excerto do fólio 114ro (MAGNE, 1970, v. 2, p. 68) e transcrição paleográfica de A. R. da Gama e C. M. Telles ${ }^{7}$

Após esse exemplo, com leituras divergentes do mesmo trecho, fica a reflexão, lembrando-se a importância do comportamento do editor. Assim, chama-se a atenção para o fato de que os critérios de transcrição e de reprodução adotados devem levar em conta a especificidade dos manuscritos estudados, bem como a necessidade de se tornar a transcrição o mais rigorosa e inequívoca possível, respeitando-se o movimento da escrita, suas hesitações, seus equívocos e as marcas dos incidentes caligráficos, como assinalam Carlos Reis e Maria do Rosário Milheiro (1989, p. 201), ainda que falem de manuscritos modernos ${ }^{8}$.

\section{EDIÇÃO CONSERVADORA DE TEXTOS NA ERA DA INFORMÁTICA}

Como se vê, ao longo de sua trajetória, a filologia abriu espaço para se debruçar sobre os mais variados textos e, atualmente, ele está abrindo espaço para outras possibilidades de apresentação dos resultados de seus trabalhos. Entre estas novas possibilidades de apresentação dos textos e suas edições encontram-se as tecnologias disponibilizadas pela informática. Ao serem introduzidas no âmbito filológico, estas tecnologias passam a merecer destaque e gerar uma série de reflexões sobre o mérito da questão (LOSE, 2006, p. 64)

Após longo período em que os recursos tecnológicos eram vistos por alguns, de certa forma, como representantes de uma ameaça ao trabalho de edição de textos antigos, agora, tecnologia e filologia andam de braços dados, reconhecidas pela maioria dos

\footnotetext{
7 Critérios usados: desenvolvimento de abreviaturas com o auxílio de parênteses; uso de chaves \{\} para indicar interpolações; palavra inserida na linha superior precedida da seta para cima $(\uparrow)$; manutenção dos sinais de pontuação do texto, ponto (.) e barra vertical (|).

${ }^{8}$ Por sua vez, é bom sempre lembrar que as normas da ABNT recomendam a "transcrição literal da fonte".
} 
pesquisadores da área como elementos indissociáveis. Desta forma, após a chegada da fotografia e do microfilme, têm-se utilizado, cada vez mais, os recursos ilimitados que diversas tecnologias da informática oferecem, em especial, computadores pessoais e câmaras fotográficas de alta resolução.

Não é sem razão que Bernard Cerquiglini compara a collatio efetuada nos antigos scriptoria com a possibilidade de leitura simultânea em várias janelas permitida na tela do computador, denominando as duas de "leituras parafrásica". Lembre-se que a variância da obra medieval levou Bernard Cerquiglini (1989, p. 111-2; 1989-1990, p. 13-4) a considerar que cada manuscrito é um remanescente, isto é uma versão.

Em seu artigo, La Paraphrase essentielle de la culture scribale (datado de 1989-1990) B. Cerquiglini compara o momento escritural dos copistas nos scriptoria às múltiplas possibilidades de leitura permitidas, nos tempos modernos, ao editor que usa o computador, relembrando que o copista dispõe muitas vezes de cópias diversas, que utiliza na preparação da cópia que está fazendo. Não nessa perspectiva, entre as cópias manuscritas e as cópias digitais permitidas pelos computadores, Maria Clara Paixão de Sousa (2009), discutindo a "mediação artificial da programação que intervém entre as etapas do [...] processamento lógico humano" (SOUSA, 2009, p. 184), explica que "[...] no meio digital o problema da 'cópia' ganha um significado interessante (SOUSA, 2009, p. 184). A seguir escreve:

De fato, a cópia digital, num certo sentido, se aproxima mais da cópia manual que da cópia mecânica, pois o processo de cópia digital inclui o re-proces-samento de etapas lógicas, de modo análogo à cópia humana, e ao contrário da cópia mecânica. A diferença aqui, é que serão as etapas lógicas artificiais que precisam se repetir. O ponto importante dessa comparação entre o processo de reprodução digital e os processos manual e mecânico é notarmos que a reprodução digital encerra um grande potencial de alterações por cópia, que remetem às etapas de processamento lógico envolvidas na difusão digital (SOUSA, 2009, p. 184).

Se se retorna ao artigo de B. Cerquiglini, pode-se verificar como ele, em 1989, conclui o seu artigo:

Pour cela, l' informatique, en tant qu'elle est une figure radicalement nouvelle de l'écrit, peut nous être d' une aide technique digne de réflexion. L'écrit écranique, en effet, est à la fois dialogique (intéraction du consultant et de la machine) et spatial (consultation conjointe, par fenêtrage, de données appartenant à des ensembles disjoints) ${ }^{9}$ (CERQUIGLINI, 1989-1990, p. 16).

$\mathrm{Na}$ sequência, sugere a edição de uma obra medieval no formato disco comportando todas as informações textuais, com possibilidade de o leitor fazer a sua escolha de leitura, concluindo, naquele momento que:

9 Traduzindo: "Por isso, a informática, enquanto é uma figura radicalmente nova do escrito, pode nos ser de uma ajuda técnica digna de reflexão. A escrita na tela do computador, com efeito, é ao mesmo tempo dialógica (interação do consulente e da máquina) e espacial (consulta simultânea, através das janelas, de dados pertencentes a conjuntos disjuntos)". 
C'est là une activité proprement éditrice, de grande ampleur, indispensable et jamais réalisée, dont seule l'informatique actuelle nous donne les moyens, et sans doute l'ídée. Car l'ordinateur, dialogique et écranique, nous restitue la prodigieuse faculté de mémoire du lecteur médiéval, qui définit sa réception esthétique et fonde le plaisir qu'il y prend, l'écrit électronique, par sa mobilité, reproduit l'oeuvre dans son activité paraphrastique même. L'informatique retrouvant, en deçà de la Modernité, le chemin d'une ancienne littérature dont l'imprimerie avait effacé la trace: c'est là un beau sujet de méditation ${ }^{10}$ (CERQUIGLINI, 1989-1990, p. 16).

\subsection{DIGITALIZAÇÃO DE DOCUMENTOS}

Entre as etapas que envolvem a produção de edições de texto atualmente está a digitalização fólio a fólio de todo o manuscrito e a utilização das imagens como recurso praticamente único para leitura dos textos, liberando o pesquisador para realizar a sua leitura e transcrição longe dos arquivos e livre dos EPIs (equipamentos de proteção individuais, como luvas e jalecos). A grande vantagem deste ponto está, principalmente, no fato de que o documento original é poupado do manuseio constante, antes indispensável para a etapa de transcrição.

No início do advento e da popularização dessa tecnologia, os primeiros processos de digitalização de fólios eram feitos com o uso de scanners de mesa de uso pessoal, que, em geral, apresentava várias desvantagens: não tinham tamanho adequado para a digitalização do fólio integral; o calor e a luminosidade emitidos por eles eram prejudiciais à conservação dos documentos e, quando se tratava de digitalizar materiais encadernados, o usuário era obrigado a abrir demasiadamente um volume, para acomodar cada fólio sobre o vidro sob o qual desliza o leitor óptico.

Atualmente, no entanto, existem diversos modelos de scanners desenvolvidos especialmente para o trabalho de digitalização de livros e documentos bibliográficos dos mais variados tipos e tamanhos, que levam em consideração a segurança, o conforto e a conservação do material digitalizado, além de primarem pela qualidade digital da imagem gerada. Porém, esses scanners especiais, em geral, têm custo demasiadamente elevado, exigindo, muitas vezes, no Brasil, custos com importação e técnicos especializados para instalação e treinamento dos usuários.

No entanto, o mais difundido e usado modo de digitalização, por sua facilidade de manuseio e custo relativamente baixo, é a digitalização feita com máquina fotográfica digital.

\footnotetext{
10 Traduzindo: "Eis aí uma atividade propriamente editorial, de grande amplitude, indispensável e jamais realizada, de que apenas a informática atual nos fornece os meios, e sem dúvida a idéia. Pois o computador, dialógico e pela tela, nos restitui a prodigiosa faculdade de memória do leitor medieval, que define sua recepção estética e encontra o prazer de que ele aí goza, o escrito eletrônica, por sua mobilidade, reproduz a obra na sua própria atividade parafrástica. A informática reencontrando, além da Modernidade, o caminho de uma anciga literatura de que a imprensa apagara o traçado: eis aí um belo assunto de meditação)".
} 
Para um trabalho realizado com mais profissionalismo podem ser usadas máquinas digitais de alta resolução, preferencialmente da categoria profissional ou semiprofissional, com boa resolução e acompanhada de lentes objetivas de boa capacidade que proporcionem alto nível de resolução e detalhe nítido.

Esta, acompanhada de outro aparelho relativamente simples e de custo não muito elevado - a mesa estativa - torna o trabalho de digitalização bastante viável.

A prática, cada vez mais comum, de digitalização dos materiais a serem transcritos, analisados, editados pelos filólogos não leva em consideração apenas a segurança dos materiais e o conforto e a liberdade do pesquisador. Como já é notório,

Esse processo de digitalização é, também, de grande valia no momento da leitura e transcrição dos documentos, pois, dispondo do recurso do zoom o pesquisador do manuscrito poderá ampliar as imagens sem perda de resolução (até um determinado limite), o que auxilia imensamente na decodificação de alguns trechos de difícil leitura e na definição de detalhes do suporte (LOSE, 2006, p. 74)

Para além de todas essas vantagens, há mais um detalhe importante em que se pensar: em caso de se estar trabalhando com documentos pertencentes a instituições, o procedimento ético recomendado é, ao final do processo de captura, organização e guarda das imagens, fornecer uma cópia dos arquivos ao arconte (o curador do acervo) da instituição. E há que ser previamente acertado com este se o material ficará ou não à disposição de outros usuários antes do término do trabalho de pesquisa ou somente após a sua conclusão.

\subsection{A EDIÇÃO DIGITAL HIPERTEXTUAL}

Para muito além dos benefícios advindos da tecnologia informática no que tange à leitura, a forma de apresentar textos preparados filologicamente também vem mudando significativamente. As transcrições passaram a ser feitas diretamente da imagem digital para os editores de texto, e as edições de textos, muitas vezes, já são apresentadas fora do modelo estático exigido pelo texto em papel.

Como se disse anteriormente, assim como nas edições tradicionais (feitas em papel), na edição através de um meio eletrônico os problemas a serem solucionados durante o trabalho de edição, como os critérios determinados para transcrição, dependerão do objetivo e da habilidade de quem está editando o texto.

"É evidente que há, desde a firmação por Lachmann, grandes modificações no método filológico, principalmente porque é o método que caracteriza a ciência." (LOSE; MAGALHÃES, 2013, p. 53) Mas o "surgimento de uma edição que nasce pensada para funcionar virtualmente não pode ser reduzido ao âmbito da forma do estabelecimento do texto.” (LOSE; MAGALHÃES, 2013, p. 53)

Aparentemente, o hipertexto apresenta-se como um meio ideal para o tratamento de edições que devem levar em consideração o ponto de vista dos movimentos de 
produção da obra, já que o formato eletrônico é infinito e flexível e pode armazenar grande quantidade de informações sob vários formatos. Ademais, permite estabelecer ligações entre as informações. O que seria bastante útil para edições de caráter crítico ou de caráter genético (LOSE, 2010). O mesmo ocorre naquelas edições em que há diversos documentos correlacionados e imagens. O hipertexto liberta o leitor da influência do editor, já que ele pode, no momento da leitura, fazer as suas escolhas e percorrer os seus caminhos.

É cada vez mais comum o filólogo utilizar, com certa intimidade, os recursos comuns disponíveis nos editores de texto, para organizações alfabéticas (através da ferramenta de classificação de texto em ordem crescente ou decrescente); para localização e substituição de trechos específicos (através da ferramenta de localização/substituição). Desta forma, parece evidente que a escolha do meio a ser utilizado esteja diretamente ligada ao tipo de edição que se há de propor. E este tipo de edição, por sua vez, está subordinada ao material com o qual se pretende trabalhar. Há que se pensar, ainda, exatamente como se deve fazer nas edições tradicionais mencionadas no início deste artigo, nos objetivos do trabalho, no público-alvo a que ela se destina, no meio que a veiculará, entre diversos outros fatores.

Portanto, o trabalho do editor, que muitos afirmam estar ameaçado em função das edições propostas com o uso das novas tecnologias, continua sendo indispensável em função das escolhas que este tem de fazer, e das adaptações dos próprios programas de computador a cada uma das idiossincrasias do texto original.

Independentemente do tipo de edição eletrônica escolhida, existem princípios uniformes para a sua criação, e estes têm historicamente como base as técnicas clássicas e já abalizadas pelos séculos de uso (LOSE, 2006, p. 64).

É indispensável ter em mente que uma edição eletrônica não é, nem de longe, uma edição convencional feita em mídia eletrônica. Portanto, o editor, ao escolher fazer uma edição em formato eletrônico deve estar atento para o fato de que as edições eletrônicas devem ser acessíveis ao maior número de usuários possível, assim precisam ser priorizados formatos simples e democráticos, compatíveis com os sistemas operacionais comuns. Além do mais, devem permitir uma utilização lógica e auto-explicativa, utilizando de fato os recursos que a tecnologia oferece. Desta forma, é interessante que as edições digitais contenham documentos multimídia e permitam o estabelecimento de ligações entre diversas informações em arquivos de formatos variados. Há que se atentar para a segurança, impedindo, da melhor forma possível, a realização de alterações não autorizadas no âmbito das edições disponíveis on-line. Por último, é sempre interessante, ainda, que as edições neste formato ofereçam a dupla possibilidade de impressão (quando autorizado) e de navegação na WEB.

Estes princípios devem ser obedecidos para que a edição digital cumpra realmente o seu papel e tenha um espaço que é só seu e que a diferencia verdadeiramente da edição estática nos moldes tradicionais (LOSE et al., 2011). 


\section{5 À GUISA DE CONCLUSÃO}

A proposta de uma edição conservadora parece ser mais do que justificada quando se considera que a scripta do documento tanto pode mostrar os erros óbvios (ou lapsus calami) - repetições, transposições, erros devidos ao contexto linguístico ou extralinguístico, os erros de concordância, as autocorreções, as adições, as omissões, as confusões de palavras (MARTÍNEZ ORTEGA, 1999) - como, o que é mais importante, as variantes textuais decorrentes do desempenho do que escreve, do responsável pela scripta.

Ao concluir essas observações, não seria ocioso lembrar que faz algum tempo se vem chamando a atenção para a importância da qualidade das edições preparadas (em termos de rigor filológico) para o estudo dos fatos linguísticos documentados nos textos e, não apenas, aqueles dos níveis fonológico e gráfico. A edição semidiplomática deve ser a primeira etapa para todo e qualquer trabalho de caráter filológico. Desse modo, tornase possível analisar os fatos linguísticos desde o nível gráfico até o discursivo.

Com o avanço tecnológico, a tarefa de proceder-se à transcrição do texto aumentou em velocidade e em variedades de formatos de apresentação. Ampliaram-se muito as possibilidades de cruzamentos de informações oferecidas aos leitores/usuários, mas a competência e a seriedade do pesquisador, que está por trás da decodificação dos caracteres e da escolha dos critérios, continua sendo o ponto mais importante para a realização de um bom trabalho filológico.

\section{REFERÊNCIAS}

BARROS, João de. 1983. Ropica pnefma. Reimp. Lisboa: Instituto Nacional de Investigação Científica. 2v. Ed. crítica de I. S. Révah.

BLANCHE-BENVENISTE, Claire. 1998a. Establecimiento del texto. In: BLANCHEBENVENISTE, Claire. Estudios lingüisticos sobre la relación entre oralidady escritura. Barcelona: Gedisa, p.129-150.

BLANCHE-BENVENISTE, Claire. 1998b. Lo Hablado y lo escrito. In: BLANCHEBENVENISTE, Claire. Estudios lingüisticos sobre la relación entre oralidad y escritura. Barcelona: Gedisa. p. 29-64.

CASTILHO, Ataliba T. de. 1995. A Língua falada e sua descrição. In: PARA SEGISMUNDO SPINA: língua, filologia e literatura. São Paulo: Iluminuras; EDUSP; FAPESP. p. 69-90.

CASTRO, Ivo de. 1988. Introdução. In: PIEL, Joseph-Maria (Edit.). A Demanda do Santo Graal. Lisboa: Imprensa Nacional; Casa da Moeda. p. ix-xxix. Ed. concl. por Irene Freire Nunes. 
CASTRO, Maria Helena Lopes et al. 1973. Normas de transcrição para textos medievais portugueses. Boletim de Filologia, Lisboa, v. 22, n. 3-4, p. 417-425.

CERQUIGLINI, Bernard. 1989. Éloge de la variante: histoire critique de la philologie. Paris: Seuil.

CERQUIGLINI, Bernard. La Paraphrase essentielle de la culture scribale. Cahiers de Linguistique Historique Médiévale, Paris, n. 14-15, p. 9-16, 1989-1990.

CINTRA, Luis F. Lindley. 1984. A Linguagem dos foros de Castelo Rodrigo, seu confronto com a dos foros de Alfaiates, Castelo Bom, Castelo Melhor, Coria, Cáceres e Usagre: contribuição para o estudo do leonês e do galego-português do século XIII. Lisboa: Imprensa Nacional; Casa da Moeda.

CUNHA, Celso. 2004. O ofício de filólogo. In: CUNHA, Celso. Sob a pele das palavras: dispersos. Rio de Janeiro: Nova Fronteira; Academia Brasileira de Letras. p. 341-359. Organização, introdução e notas de Cilene da Cunha Pereira.

DERRIDA, Jacques. 2001. Mal de arquivo: uma impressão freudiana. Tradução: Cláudia de Moraes Rego. Rio de Janeiro: Relume Dumará.

DIAS, João José Alves (Edit.). 1982. Livro dos conselhos de El-Rei D. Duarte: livro da Cartuxa. Lisboa: Estampa. Introd. de A. H. de Oliveira Marques e João José Alves Dias, rev. de A. H. de Oliveira Marques e Teresa F. Rodrigues.

DIONÍSIO, João. 2007. Criticus fit. Veredas: Revista da Associação Internacional de Lusitanistas, Porto Alegre, v. 8, p. 104-125.

DUARTE, Luiz Fagundes. 2007. Tempo de perguntar. Veredas: Revista da Associação Internacional de Lusitanistas, Porto Alegre, v. 8, p. 11-29.

ECO, Umberto. 2003. Sobre a literatura. Tradução: Eliana Aguiar. Rio de Janeiro: Record.

FERREIRA, José de Azevedo (Edit.). 1980. Alphonse X, Primeyra partida: édition et étude. Braga: Instituto Nacional de Investigação Científica.

FOWLER, Roger. 1994. Crítica lingüistica. Tradução: Maria Luísa Falcão e Isabel Mealha. Lisboa: Calouste Gulbenkian.

FRÈCHES, Claude-Henri. 1986. Manuscrits d'inquisition au XVIII ${ }^{\mathrm{e}}$ siècle. Difficultés de lecture et d'interprétation. In: CRITIQUE TEXTUELLE PORTUGAISE: actes du Colloque (Paris, 20-24 octobre 1981). Paris: Fondation Calouste Gulbenkian; Centre Culturel Portugais. p. 301-310.

GAMA, Albertina Ribeiro da; TELLES. Célia Marques. 2001. A Lição conservadora e a análise linguística do texto. In: SOARES, Maria Elias (Org.). Congresso Internacional da ABRALIN, 2; anais. Fortaleza: ABRALIN. v. 1, p. 463-5. (Boletim da ABRALIN, 26). 
GÂNDAVO, Pêro de Magalhães de. 1965. Tratado da Província do Brasil. Rio de Janeiro: MEC; INL. Ed. prep. por Emmanuel Pereira Filho.

GRÉSILLON, Almuth; LEBRAVE, Jean-Louis. 1983. Avant-propos. Langages, Paris, n. 69, p. 5-10, mars. "Manuscrits-écriture, production linguistique".

LLORED, Patrick. 2001. La Philologie comme art critique. Autours de l'oeuvre de Jean Bollack. Esprit, Paris, n. 278, oct.

LOSE, Alicia Duhá. 2010. Edição digital de texto manuscrito: filologia no séc. XXI. Estudos Linguísticos e Literários, n. 41, p. 11-30, jul./dez.

LOSE, Alícia Duhá. 2006. A Crítica textual e as novas tecnologias. In: TEIXEIRA, Maria da Conceição Reis; QUEIROZ, Rita de Cássia; SANTOS, Rosa Borges dos (Org.). Diferentes perspectivas dos estudos filológicos. Salvador: Quarteto. p. 63-78.

LOSE, Alícia Duhá et al. 2011. Edições digitais de manuscritos: do século XVI ao século XXI. In: CIRILLO, José; PASSOS, Marie-Hélène Paret (Org.). Materialidade e virtualidade no processo criativo. Vinhedo, SP: Horizonte, 2011. p. 77-99.

LOSE, Alícia Duhá; MAGALHÃES, Lívia Borges Souza. Da pena às tags e dígitos binários: os caminhos da filologia textual no século XXI. In: ROMANELLI, Sérgio. Compêndio de Crítica Genética América Latina. Vinhedo, SP: Horizonte, 2013. p. 51-57.

MAGNE, Augusto, S.J. (Edit.). 1970. A Demanda do Santo Graal: reprodução fac-similar e transcrição crítica do códice 2594 da Biblioteca Nacional de Viena. Rio de Janeiro: MEC; INL. v. 2.

MAN, Paul de. 1989. A Resistência à teoria. Tradução: Teresa Louro Pérez. Lisboa: Edições 70.

MARCUSCHI, Luiz Antônio. 2001. Da fala para a escrita: atividades de retextualização. 2. ed. São Paulo: Cortez.

MARTÍNEZ ORTEGA, María de los Ángeles. 1999. El Error gráfico o lapsus calami en los textos jurídicos. In: MARTÍNEZ ORTEGA, María de los Ángeles. La Lengua de los siglos XVI y XVII a través de los textos jurídicos: los pleitos civiles de la escribanía de Alonso Rodríguez. Valladolid: Secretariado de Publicaciones; Intercambio; Universidad de Valladolid. p. 23-42.

MEGALE, Heitor (Edit.). 1988. A Demanda do Santo Graal (manuscrito do século XIII). São Paulo: T. A. Queiroz; EDUSP. p. 268-9.

NUNES, Irene Freire (Edit.). 1995. A Demanda do Santo Graal. Lisboa: Imprensa Nacional; Casa da Moeda. 
PICCHIO, Luciana Stegagno. 1979. O método filológico (Comportamentos críticos e atitude filológica na interpretação de textos literários). In: PICCHIO, Luciana Stegagno. A lição do texto, filologia e literatura: I - Idade Média. Lisboa: Edições 70. p. 209-235.

PIEL, Joseph-Maria (Edit.). 1934/1988. A Demanda do Santo Graal. Lisboa: Imprensa Nacional; Casa da Moeda. Concl. por Irene Freire Nunes.

PIEL, Joseph M. (Edit.). 1986. Livro da ensinança de bem cavalgar toda sela que fez. El-Rey Dom Eduarte de Portugal e do Algarve e Senhor de Ceuta. Lisboa: Imprensa Nacional; Casa da Moeda.

PIEL, Joseph M. 1945. Anotações críticas ao texto da Demanda do Graal. Biblos, Coimbra, v. 21, p. 175-206.

REIS, Carlos; MILHEIRO, Maria do Rosário. 1989. A Construção da narrativa queirosiana: o espólio de Eça de Queirós. Lisboa: Imprensa Nacional; Casa da Moeda.

SAUSSURE, Ferdinand de. 2004. Escritos de lingüística geral. Trad. de Carlos Augusto Leuba Salum e Ana Lúcia Franco. São Paulo: Cultrix. Org. e edit. por Simon Bouquet e Rudolf Engler.

SOUSA, Maria Clara Paixão de. Conceito material de "texto digital": um ensaio. Texto Digital, Florianópolis, UFSC, v. 5, n. 2, p. 159-187, 2009. Disponível em: https://periodicos.ufsc.br/index.php/textodigital/article/view/1807. Acesso em 26.10.2016.

SPINA, Segismundo. 1988. Prefácio. In: MEGALE, Heitor (Edit.). A demanda do Santo Graal (manuscrito do século XIII). São Paulo: T. A. Queiroz; EDUSP. p. xiii-xvi.

SPINA, Segismundo. 1994. Normas gerais para os trabalhos de grau: um breviário para o estudante de pós-graduação. São Paulo: Ática.

TEBEROSKY, Ana. 1998. Introducción. In: Claire BLANCHE-BENVENISTE. Estudios lingüisticos sobre la relación entre oralidad y escritura. Barcelona: Gedisa. p. 9-17.

TELLES, Célia Marques. 2009. A Chamada lição conservadora na edição de textos. Scripta Philologica, Feira de Santana (BA), n. 5, p. 253-266.

TELLES, Célia Marques. 2005. Literatura e filologia. In: JOBIM, José Luís (Org.). Encontro regional da ABRALIC: sentido dos lugares. Rio de Janeiro: ABRALIC; UERJ. p. 1-18. Grupo temático: "O lugar ou os lugares dos textos literários: questões de crítica textual e estudos literários”.

TELLES, Célia Marques. 2000. Mudanças lingüísticas e crítica textual. Estudos Lingüisticos e Literários, Salvador, n. 25-26, p. 94-5 jan.-dez.

VASCONCELOS, Carolina Michaëlis de. 1946. Lições de filologia portuguesa: segundo as preleções feitas aos cursos de 1911/12 e de 12/13, seguidas das "Lições de português arcaico". Lisboa: Revista de Portugal. 
WRIGHT, Roger. 1998. Cambios linguísticos y cambios textuales. IN: BLECUA, José Manuel; GUTIÉRREZ, Juan; SALA, Lidia (Org.). Estudios de grafemática en el dominio español. Salamanca: Univ. de Salamanca. p. 303-308.

Recebido em: 02/05/2017

Aprovado em: 08/08/2017

Publicado em: 01/12/2017 